\title{
Interactive Design in Enhancing User Experience in Museum
}

\author{
Romiza Md Nor ${ }^{*}$, Muhammad Hafizuddin Abdul Razak ${ }^{2}$ \\ ${ }^{1,2}$ Faculty of Computer and Mathematical Sciences, \\ Universiti Technologi MARA, Perlis Branch, Arau Campus, 02600 Arau, Perlis, Malaysia
}

Corresponding author: "romiza@uitm.edu.my

Received Date: 20 August 2021

Accepted Date: 27 August 2021

Published Date: 13 September 2021

\section{HIGHLIGHTS}

- Interactive design principles were used to design the museum mobile application

- The mobile AR application is developed using Unity, Blender and Vuforia

- User experience evaluation method is used to measure users' satisfaction and usability of the developed mobile application

\begin{abstract}
A museum can be a suitable context to experiment with a new interaction technique which guiding visitors and improving their experience for a successful learning environment also to enrich user experience. Mobile technology is used to enhance user experience in a cultural environment that offers more information than physically exposed technology. Therefore, the introduction of augmented reality (AR) that allow visitor to experience interaction in a way that increased knowledge, learning and give additional information with any artefact exhibitions they interact in the museum is applied in this project. The objectives of this research are to develop an interactive design in enhancing user experience in artefact display and evaluate user experience. ADDIE Model is applied as the methodology that consists of five phases which are analysis, design, development, implementation, and evaluation. Principles of Interactive Design is utilized in designing the mobile AR application and developed using Unity, Blender and Vuforia. User Experience evaluation method is conducted where findings shows that most respondents are satisfied, and usage of mobile AR has enhanced their experience through navigation during museum visit that also give a lot of new insight on historical artefact that being displayed.
\end{abstract}

Keywords: Interactive design, user experience, augmented reality, museum artefact

\section{INTRODUCTION}

A museum can be a suitable context to experiment with a new interaction technique which guiding visitors and improving their experience. Museum environment is suitable for a successful learning environment and to enrich user experience. Currently, museum faces the challenge of attracting visitors who are less mobile which is financially and physically visit the museums. One way to make exhibitions more appealing for the visitor is to enhance the interaction between the visitor and the objects of interest through a guide (Bay, Fasel, \& van Gool, 2006). They also stated that visitor would be interested if they can interact with the exhibitions in the museum rather than just staring and reading the information about the artefacts. Audience Finder benchmark data indicated that regular visitors are more likely to perceive museums as a place of 
entertainment. However, learning is the most consistent motivation for visiting museums across all age groups. Introduction of new technologies in the cultural environment has enriched the way the objects are shown to visitors (Tesoriero, Gallud, Lozano, \& Penichet, 2014).

This technology offers more information than physically exposed technology. Furthermore, the introduction of augmented reality in mobile applications at the museums could increase user experience satisfaction and their motivation towards learning and entertainment.

Interactive design allows interaction between user and exhibitions. The interaction involves physical manipulation such as clicking buttons or flicking a switch in response to specific questions or demands presented on screens (Haywood \& Cairns, 2006). The interactive design has five dimensions of interactive design which are the word, visual representations, physical objects or space, time, and behaviours. It will help the user to understand, guide and give more information related to museum exhibition.

User experience depends a lot more on application than augmented reality. It depends more on usability and solves the problem using augmented reality. In order to have something to be meaningful and valuable user experience, the information must be useful, usable, desirable, findable, accessible and credible. User experience understands users' motivations in using a product whether it relates to a task they wish to perform. The product can be relating to the design of functionality in an accessible and aesthetically pleasant way. So, augmented reality also can be a potential interaction that enhances user experience against exhibitions which provide additional information related to an object or display (Berryman, 2012).

This project focus on visitors who visit Kota Kayang Museum to enhance user experience when visiting the museum. Visitors use the mobile applications in the museum which allow them to interact with the artefact exhibitions in the museum. The interaction with the application enhanced usability toward user experience. Augmented reality is integrated with mobile applications to give more interactive experience.

\section{METHODOLOGY}

The methodology applied in the research is ADDIE Model (Drljaca et al., 2017) where all five phases are followed. This project is design by applying principles of interactive design consistency, perceivability, learnability, predictability, and feedback. The mobile application is developed using Unity, Blender and Vuforia. User Experience evaluation method is conducted and evaluated using principle of user experience and results are explained in findings and discussion section.

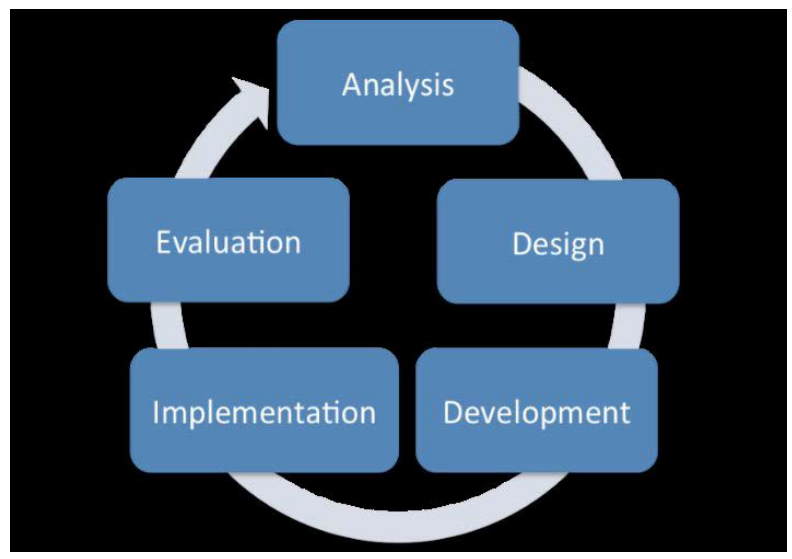

Figure 1: ADDIE Model

(Source: https://educationaltechnology.net/the-addie-model-instructional-design/) 


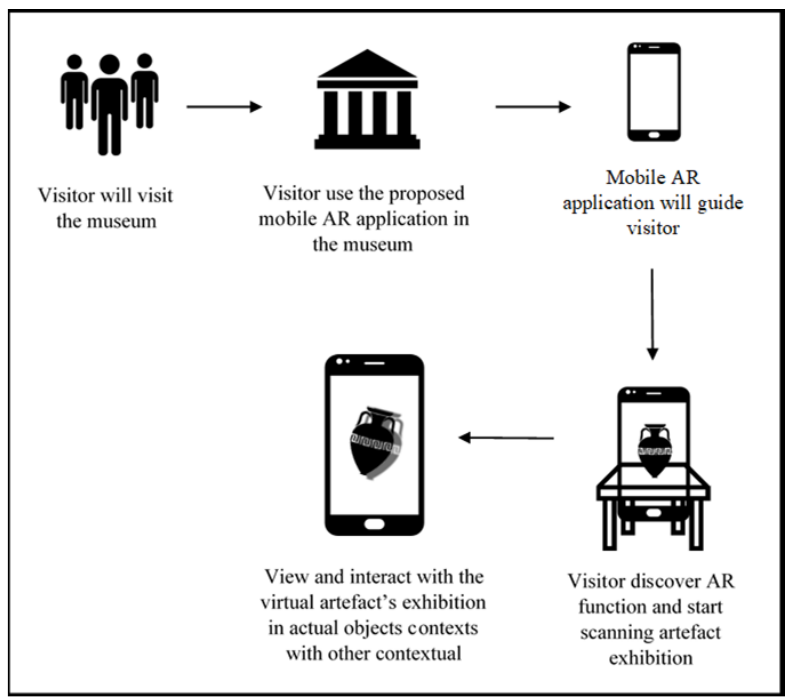

Figure 2: Experimental design

Experimental design in Figure 2 shows overview on the visitor interaction with mobile AR application when they visited the museum. 3D model of artefact is created to provide visitor with opportunity to view virtual artefact in actual object contexts and other contextual information.

\section{Principle of Interactive Design}

Principles of interactive design generates meaningful experiences and provides interactivity by focusing on human cognitive processing capacity and limitations. In interactive design, a human can be an expert but also a user. Development of interactive design focus on the centering of product engineering on human. Relationships between people and products are critical because interactive design generates meaningful experiences and provides interactivity by focusing on human cognitive processing capacity and limitations. There are five essential core principles of interactive design which help focus on providing better solutions, experiences and designs ("5 Essential Core Principles of Interactive Design", 2016). Figure 3, 4, 5 and 6 shows how all five principles of interactive design are applied in the design of the mobile application.

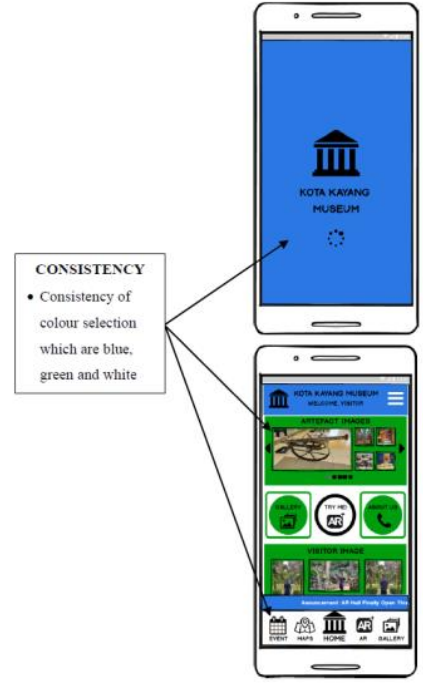

Figure 3: Interactive design principle: Consistency

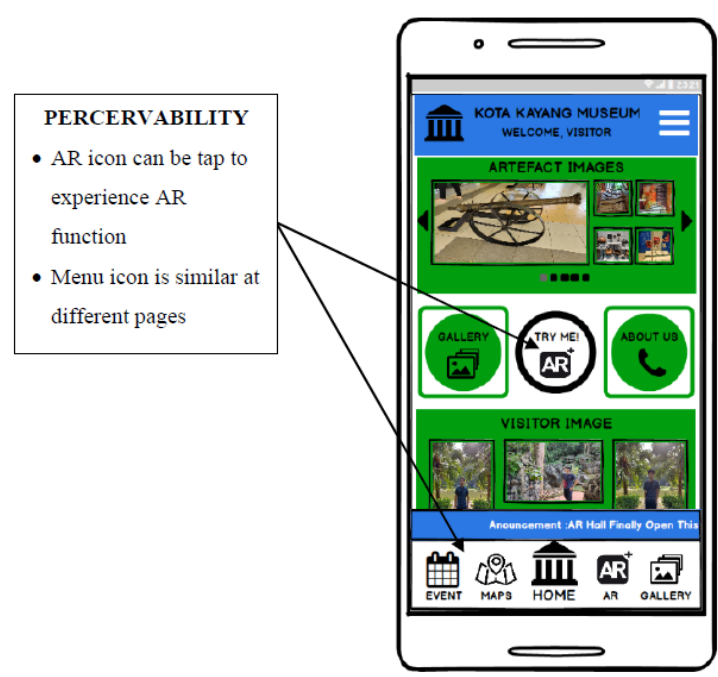

Figure 4: Interactive design principle: Perceivabilty 


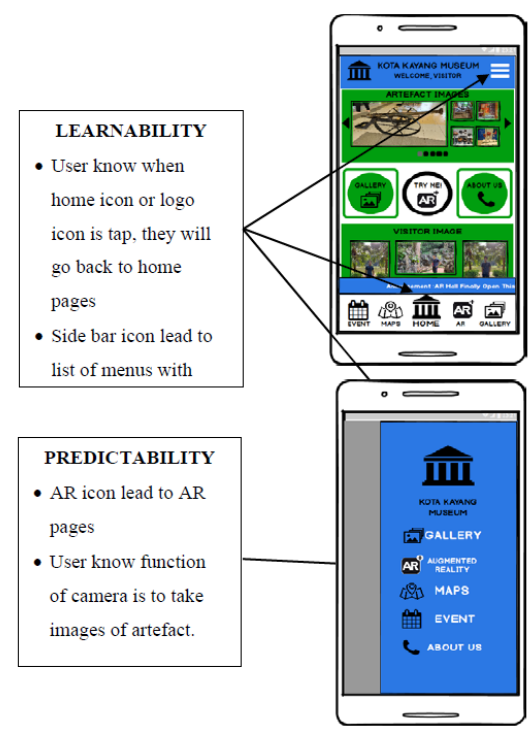

Figure 5: Interactive design principle: Learnability and Predictability

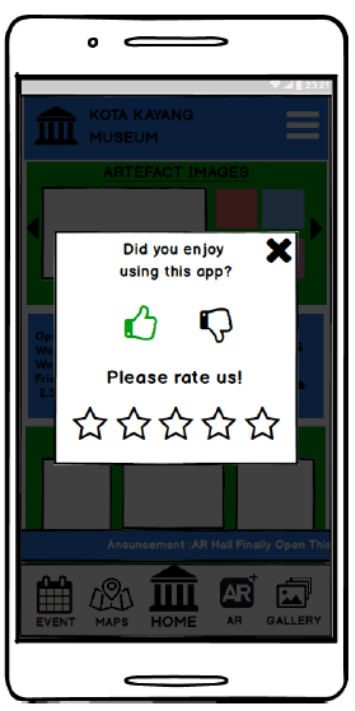

Figure 6: Interactive design principle: Feedback

\section{FINDINGS AND DISCUSSIONS}

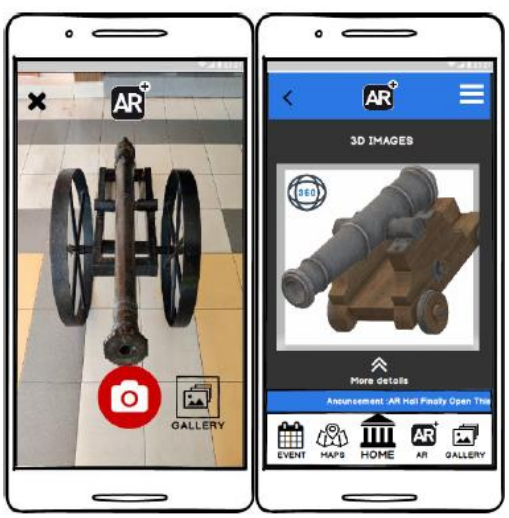

Figure 5: Artefact display via augmented reality

User Experience evaluation method is conducted to measure how usable and to determine the user's satisfaction of the mobile application. There are 30 respondents from different education and background. Observation was conducted where user is given briefed description of the mobile application. Then user is observed to complete all tasks on the mobile application before questionnaire is distributed. There are four sections in the questionnaire which are Section A (Words), Section B (Visual representation), Section C (Physical object and space) and Section D (Behaviour). Each principle is rated using a scale of Strongly Disagree (1) to Strongly Agree (5). All dimensions received mean score of above 4, which indicated that generally, the mobile application received good evaluation.

In Section A (Words), stated that it should be able to interact or communicate between product and the users. This section show that the selection of button, icons, text and word is very familiar to understand to use the application. In Visual representation section, users commented that in this application is a success where this mobile application display picture of museum artefact, 3D model of artefact and provide information to visitors as shown in Figure 7. The Augmented Reality features manage to increase users' 
satisfaction during the interaction. The AR camera is easy to use where they only need to direct their camera to the picture of the artefact and the AR Vuforia feature will render 3D model of the artefact. The implementation of Physical objects and space principle manage dimension that includes the medium by which user interacts via the fingers with the mobile application. Users found that they are engaged with the mobile application since they can move around easily with the artefact with the assistance of the button and zoom function. Lastly, last dimension is Behavior that concerned with defining the interactions of the product with the previous four dimensions. For example, its concern about what users can do on an app or website and how users use the product. Besides, behavior also means how the product reacts to the input of users and offers feedback. In short, all five dimensions consider the interactions between a user and a product in a holistic way. They are likely to touch more and want to experience more of the feedback. For example, the mobile application able to provide feedback such as popup messages when users exit the application. This shows the concern for users when users make decision. This feature also increases user satisfaction toward the application. Therefore, usage of mobile AR has enhanced their experience through navigation during museum visit that also give lot of new insight on historical artefact that being displayed.

From the user experience evaluation, users raised concerns and recommended some solutions to improve the mobile application. Features in the Augmented Reality 3D objects feature can be enhanced to be more realistic similar with reality object. Users also suggested that researcher can input some avatar which can tell information or give guide to visitor. More animation, effect to create virtual world where people can enjoy and have fun at the same time learn about the history of artefact displayed.

\section{CONCLUSION AND RECOMMENDATIONS}

The AR museum mobile application is an interactive design application which can enhance user experience on artefact display. This mobile AR application is design for visitor who visit the Kota Kayang Museum as it helps them to find information, interact with the artefact, gain knowledge about history and gain new experience using Augmented Reality. The Principle of Interactive Design and User Experience evaluation method help to measure user satisfaction when they interact with the application and experience Augmented Reality. In conclusion, the objectives of this research have been achieved where the system has been successfully designed and developed according to predefined requirements.

\section{REFERENCES}

5 Essential Core Principles of Interactive Design (2016, September 21). Retrieved from https://cristianweierick.wordpress.com/2013/10/30/5-essential-core-principles-of-interactive-design-2/

Bay, H., Fasel, B., \& van Gool, L. (2006). Interactive Museum Guide: Fast and Robust Recognition of Museum Objects. Proceedings of the First International Workshop on Mobile Vision. Retrieved from http://eprints.pascal-network.org/archive/00002403/

Berryman, D. R. (2012). Augmented Reality: A Review. Medical Reference Services Quarterly, 31(2), 212-218. https://doi.org/10.1080/02763869.2012.670604

Drljača, D., Latinović, B., Stanković, Ž., \& Cvetković, D. (2017). ADDIE Model for Development of ECourses. 242-247. https://doi.org/10.15308/sinteza-2017-242-247 
Ghouaiel, N., Garbaya, S., Cieutat, J.-M., \& Jessel, J.-P. (2016). Mobile Augmented Reality in Museums: Towards Enhancing Visitor's Learning Experience. The International Journal of Virtual Reality, 17(1), $21-31$.

Haywood, N., \& Cairns, P. (2006). Engagement with an interactive museum exhibit. People and Computers XIX - The Bigger Picture, Proceedings of HCI 2005, 113-129.

Tesoriero, R., Gallud, J. A., Lozano, M., \& Penichet, V. M. R. (2014). Enhancing visitors' experience in art museums using mobile technologies. Information Systems Frontiers, 16(2), 303-327. https://doi.org/10.1007/s10796-012-9345-1 